\title{
Outras Abordagens Para os Corpos nos Espaços Escolares
}

\author{
Otros Enfoques Para los Cuerpos en los Espacios Escolares
}

\section{Other Approaches to Bodies in Spaces School}

\author{
Ma. Taina Guerra Chimiesk ${ }^{1}$ \\ Dra. Raquel Pereira Quadrado ${ }^{2}$
}

\begin{abstract}
Resumo
Este artigo tem como objetivos conhecer as motivações que levaram quatro docentes a utilizar o livro paradidático "Os 15 anos de Mariana: um convite a outras aprendizagens sobre corpos" e compreender que tipo de corpo tal material possibilita ser discutido na escola. Para tal, realizamos entrevistas semiestruturadas com quatro professores/as de ciências. A produção e a análise dos dados ocorreram a partir da metodologia de investigação narrativa. As análises indicam que a linguagem narrativa do livro associado a temática, que estabelece relação com os/as estudantes, foram fatores que motivaram a utilização do livro. Além disso, o trabalho desenvolvido a partir deste material possibilitou entender os corpos como construções biossociais.
\end{abstract}

Palavras-chave: corpos, ensino, docentes.

\section{Resumen}

Este artículo tiene como objetivo comprender las motivaciones que llevaron a los profesores a utilizar el libro paradidáctico "Los 15 años de Mariana: una invitación a aprender otra en los cuerpos" y entender que clase de cuerpo el libro permite que ser discute en la escuela. Con este fin, se realizaron entrevistas semiestructuradas con cuatro profesores / la ciencia. La producción y el análisis de los datos se produjeron a partir de la metodología de investigación narrativa. Los análisis indican que el lenguaje narrativo del libro asociado con el tema, que tiene relaciones con los estudiantes, fueron factores que motivaron el uso del libro. Además, el trabajo con este libro hace posible entender el cuerpo como un construcciones bio-sociales.

Palabras claves: cuerpos, educación, maestros.

\section{Abstract}

This article aims to understand the motivations that led four professors to use the paradidactic book "Os 15 anos de Mariana: um convite a outras aprendizagens sobre corpos" and understand what kind of body this one material allows to be discussed in school. To this end, we conducted semistructured interviews with four teachers the science. The production and analysis of data occurred from the narrative research methodology. The analyzes indicate that the narrative language of the book and the theme of establishing relations with students, were factors that motivated the use of the book. In addition, the work from this material made it possible to understand the body as a bio-social constructions.

Keywords: bodies, teaching, teachers.

\footnotetext{
${ }^{1}$ Mestra em Educação; Universidade Federal de Rio Grande; FURG, Rio Grande, Rio Grande do Sul, Brasil. taina.bio@hotmail.com

${ }^{2}$ Doutora em Educação em Ciências: Química da vida e saúde; Universidade Federal de Rio Grande; FURG, Rio Grande, Rio Grande do Sul, Brasil. raquelquadrado@hotmail.com
} 


\section{Contextualização}

Nas últimas décadas, o currículo escolar tem estado no centro de discussões do campo da educação, as quais nos possibilitam problematizar seu papel e sua importância nas instituições escolares. Entre tais discussões, a mais atual é a proposta de uma Base Nacional Curricular Comum, que especifica quais são os conhecimentos essenciais a ser propiciados aos/as ${ }^{3}$ estudantes da Educação Infantil ao Ensino Médio. Seu objetivo é garantir maior unificação ao currículo escolar brasileiro.

Ao olharmos para o currículo, é importante percebê-lo como uma construção social e histórica marcada por relações de poder. Assim, produz visões particulares do mundo ao legitimar ou excluir determinados conhecimentos que devem fazer parte das práticas de ensino-aprendizagem.. Por isso, entendemos que o currículo não é " [...] um meio neutro de transmissão de conhecimentos ou informações. [...] Ao determinar quem está autorizado a falar, quando, sobre o quê, quais conhecimentos são autorizados, legítimos, o currículo controla, regula, governa" (SILVA, 2013, p.196).

Ao analisarmos os currículos escolares atuais, é possível perceber que grande parte apresenta-se de forma fragmentada, descontextualizada, marcada por não representar a realidade dos estudantes e por abordar conteúdos isolados de seu contexto histórico, sociocultural e político. Essa compartimentalização também pode ser observada nos livros didáticos, que, assim como os currículos, desconsideram a diversidade cultural e privilegiam visões hegemônicas da sociedade, tornando-se desinteressantes para os/as estudantes por não estabelecer significado para os/as mesmos/as.

Buscando romper com essa fragmentação, especialmente na forma como o corpo humano vem sendo abordado pelos currículos e pelos livros didáticos, foi produzido o livro paradidático "Os 15 anos de Mariana: um convite a outras aprendizagens sobre corpos" ${ }^{4}$. A partir do estabelecimento de uma parceria entre a Universidade Federal do Rio Grande FURG e a Prefeitura do Município, o material foi distribuído aos/as professores/as de ciências pertencentes à rede municipal de ensino, no intuito de que os corpos possam ser discutidos como uma produção marcada histórica e culturalmente.

3 . Buscando visibilizar o gênero feminino, nesta pesquisa, utilizaremos a flexão de gênero para nos referirmos aos gêneros.

4 . RIBEIRO, Paula Regina Costa; LONGARAY, Deise Azevedo (org.) Os 15 anos de Mariana: um convite a outras aprendizagens sobre corpos. Rio Grande: FURG, 2013. 144p. Essa obra paradidática propõe abordar o corpo como uma construção biossocial. Sua produção foi possibilitada pelo projeto Ciência, Universidade e Escola investindo em Novos Talentos, na Universidade Federal do Rio Grande - FURG. 

e-ISSN 2016/Atual: 2525-7870 | e-ISSN 2015/2016: 2447-018X

Este artigo encontra-se ancorado na perspectiva dos Estudos Culturais em sua vertente pós-estruturalista e objetiva conhecer as motivações que impulsionaram os/as docentes a utilizar o livro de Mariana em suas práticas, bem como compreender que tipo de corpo o material possibilita discutir na escola. Para tanto, analisamos as narrativas de quatro docentes que têm feito uso do material paradidático mencionado em suas práticas. Tais narrativas foram produzidas a partir de entrevistas semiestruturadas e foram analisadas a partir da estratégia de investigação narrativa. Antes de apresentá-las, cabe problematizar como os corpos têm sido pensados nos currículos escolares.

\section{Problematizando os Corpos Produzidos Pelos Currículos Escolares}

O corpo presente nos currículos escolares é o corpo descrito pela ciência, repleto de músculos, vísceras, órgãos, cuja relevância está nos nomes e nas funções atribuídas a cada uma de suas partes. Assim, esse foco concedido ao corpo humano o reduz à categoria de organismo, visto que a abordagem apresentada é pautada apenas pelo discurso científico. No entanto, compreendemos que os corpos são constituídos através das relações estabelecidas entre a materialidade biológica e a cultura, ou seja, os múltiplos discursos que os interpelam nos distintos meios sociais em que transitam, como a escola, a igreja, os programas televisivos aos quais assistimos, o grupo familiar, entre outros.

Ao eleger o biológico como único discurso para conduzir as discussões sobre corpos, o currículo prioriza uma visão hegemônica, tida como legítima, e acaba por silenciar a produção de outros saberes, tais como aqueles provenientes da cultura, das experiências e das vivências dos/as sujeitos nos diversos meios sociais, como apontam Tatiana Camargo e Nádia Souza:

[...] entendemos que a educação escolarizada é um espaço privilegiado no aprendizado de conhecimentos sobre o corpo e os cuidados de si. No entanto, as práticas escolares, especialmente aquelas relacionadas ao ensino de ciências e de biologia, ao centrarem suas abordagens na visão biológica de corpo - presente nos livros didáticos e nos Programas escolares, regida pelas disciplinas acadêmicas -, deixam de incluir em suas discussões os saberes e "conteúdos" produzidos por pedagogias que ensinam "fora" do ambiente escolar. Essa tradição escolar vem impedindo a produção de um outro saber crítico e relevante para a vida das pessoas, capaz de fazer frente às múltiplas "verdades" que inscrevem e regulam os seus corpos (2012, p. 76) [grifos das autoras].

Entendemos que o corpo não pode ser reduzido à fisiologia e à anatomia, posto que “[...] é formado por uma série de regimes que o constroem; ele é destroçado por ritmos de trabalho, repouso e festa; ele é intoxicado por venenos - alimentos ou valores, hábitos 
alimentares e leis morais simultaneamente; ele cria resistências" (FOUCAULT, 2014, p. 72). Assim, ao abordá-lo apenas pelo viés biológico, a escola estará atuando na produção e na reprodução de "verdades" sobre ele, baseando-se no entendimento de que a ciência é incontestável. Logo, o enfoque dado a essas discussões deve seguir unicamente por esse viés (QUADRADO, 2012). Dessa forma, a rede polissêmica de discursos que atuam na produção dos corpos é desconsiderada, o que promove uma homogeneização no currículo., silenciando, por exemplo, as diferenças culturais de raça, de crenças e de gênero.

O corpo abordado nas escolas é estanque, diferente dos corpos dos/as estudantes e dos/as professores/as que são mutantes e estão em constante processo de (re)significação. Em função do ensino fragmentado, focado no organismo, muitas vezes os/as estudantes não conseguem se identificar e estabelecer uma relação entre o corpo/organismo, ensinado pela escola, e o seu corpo. Em virtude disso, consideramos possíveis outras abordagens para o assunto corpos, como, por exemplo, práticas escolares que considerem os múltiplos discursos envolvidos na sua produção - e não apenas o discurso biológico.

Em virtude disso, foi produzido o livro paradidático "Os 15 anos de Mariana: um convite a outras aprendizagens sobre corpos". A obra apresenta possibilidades de pensar o corpo como um constructo biossocial, ou seja, uma produção que se exerce na relação entre o biológico e as práticas sociais em que nos encontramos imersos. Sua escrita é direcionada aos/as professores/as de ciências, no intuito de que encontrassem nesse material um aporte para problematizar os corpos além do discurso biológico presente nos livros didáticos. Embora nosso foco de análise não seja a obra mencionada, mas as práticas por ela oportunizadas, cabe-nos apresentar brevemente tal material.

\section{Conhecendo o livro "Os 15 anos de Mariana: um convite a outras aprendizagens} sobre corpos"

Os livros paradidáticos têm por objetivo auxiliar os/as professores/as no desenvolvimento de suas práticas. Seu propósito não é substituir os livros didáticos, mas ser utilizados junto a eles. De acordo com Jimena Furlani (2005), tais obras podem ser descritas como:

[...] instrumentos de ensino e são frequentemente atualizados. Entretanto, geralmente, seus conteúdos relacionam-se a temáticas que tangenciam as disciplinas do currículo oficial. Assim, são vistos como um complemento aos livros didáticos e, mesmo que cada disciplina ofereça uma gama de conteúdos, os livros paradidáticos são elaborados especificadamente para cada assunto, por exemplo: educação sexual, meio ambiente, pluralidade cultural, ética, prevenção de drogas, cidadania, direitos humanos, direitos dos consumidores (FURLANI, 2005, p. 19). 
O livro "Os 15 anos de Mariana: um convite a outras aprendizagens sobre corpos", embora problematize um tema presente no currículo escolar e nos livros didáticos, o corpo humano, busca apresentar novos olhares para tal temática. A sua produção ocorreu no âmbito do projeto Ciência, Universidade e Escola: investindo em novos talentos, que tem entre seus objetivos a produção de materiais didáticos pedagógicos. Tal projeto resulta de um convênio existente entre Universidade Federal do Rio Grande - FURG, através do Centro de Educação Ambiental e Matemática (CEAMECIM), a Financiadora de Estudos e Projetos (FINEP), a Coordenação Nacional de Ensino Superior (CAPES) e o Instituto Nacional de Ciência e Tecnologia em Excitocidade e Neuroproteção (INCTEN/UFRGS/CNPQ).

Sua produção ocorreu a partir de diálogos entre pesquisadores/as da FURG, que vêm desenvolvendo pesquisas em relação ao tema, e integrantes do Grupo de Estudos e Pesquisas em Educação em Ciências (GEPEC). Foram organizados dois livros, um direcionado aos/as estudantes e outro aos/às professores/as, que, além da história da Mariana, apresenta um aporte teórico que articula questões biológicas, sociais, culturais, históricas e pedagógicas sobre o ensino dos corpos (RIBEIRO E LONGARAY, 2013).

Lançado no ano de 2013, foi distribuído às escolas municipais do Rio Grande que possuem os Anos Finais do Ensino Fundamental, através da Secretaria do Município da Educação (SMED). Cada escola recebeu para sua biblioteca um kit contendo trinta (30) exemplares do livro do/a aluno/a e os/as professores/as de ciências receberam um (1) exemplar para uso pessoal. Tal ação foi possível devido a uma parceria existente entre a Prefeitura Municipal e a Universidade Federal do Rio Grande - FURG.

A história de Mariana contém sessenta e seis (66) páginas e está dividida em sete (7) capítulos, nos quais são narradas as experiências de Mariana, seus/as amigos/as e familiares até o dia da sua festa de aniversário. As páginas são coloridas, cada capítulo tem uma cor diferente e inicia com uma ilustração referente ao que será abordado. O livro apresenta, assim, um caráter lúdico e conta com ilustrações e quadros no meio do texto, como o Fala Mais! e o Você Sabia, que exploram determinados assuntos relacionados a drogas, substâncias que compõem o cigarro, Alzheimer, salto alto e protetor solar, além de apontar curiosidades sobre o corpo humano, como, por exemplo as causas do gigantismo e do nanismo, como se formam as estrias, ciclo menstrual, entre outros.

Acreditamos que a temática do livro, seu aspecto lúdico e a forma com que explora o corpo humano possibilitam aos/às estudantes um envolvimento com a história capaz de contribuir para uma aprendizagem que estabelece conexão com o seu cotidiano. Por isso, 
buscamos conhecer como esse recurso tem sido utilizado nas escolas. Para tal, realizamos quatro entrevistas semiestruturadas com professores/as de ciências que narraram como vêm fazendo uso do livro em suas práticas docentes.

\section{Delineando o Pressuposto Metodológico}

Ancoradas na perspectiva da investigação narrativa, buscamos, através de entrevistas semiestruturadas, ouvir as histórias, as experiências e as trajetórias de quatro professores/as participantes da pesquisa. De acordo com Michael Connelly e Jean Candinin, esse processo de escutar é importante, pois significa dizer "[...] a quien durante mucho tempo se le há silenciado em relación de investigación, se le está dando el tempo y el espacio para que cuente su historia, y para que su historia también gane la autoridade y la calidez que han tenido siempre los relatos de investigación" (1995, p. 21).

Dessa maneira, o trabalho com as narrativas tem por objetivo tornar o/a participante visível para si mesmo. Ao narrar suas experiências, os/as docentes estavam construindo e reconstruindo suas experiências, significando e (re)significando suas histórias. Assim, a narrativa pode ser entendida como uma prática social imbricada na produção dos sujeitos, visto que ao contar e ao ouvir histórias vamos produzindo a nossa própria história. Como nos diz Jorge Larrosa:

[...] cada um de nós se encontra já imerso em estruturas narrativas que lhe preexistem e que organizam de um modo particular a experiência, que impõem um significado à experiência. Por isso, a história de nossas vidas depende do conjunto de histórias que temos ouvido, em relação às quais temos aprendido a construir a nossa.[...] A construção do sentido da história de nossas vidas e de nós mesmos nessa história é, fundamentalmente, um processo interminável de ouvir e ler histórias, de mesclar histórias, de contrapor umas histórias a outras, de viver como seres que interpretam e se interpretam em tanto que estão se constituindo nesse gigantesco e agitado conjunto de histórias que é a cultura (1996, p. 461-462).

Entendemos que a história de nossas vidas é constituída por muitas histórias, "nossa história é sempre uma história polifônica” (id. p. 465). Logo, é no gigantesco e agitado encontro de narrativas que nos inventamos, produzimo-nos, modificamo-nos e construímos a nossa subjetividade.

Partindo do pressuposto de que a investigação narrativa proporciona a utilização de diversas estratégias para a produção dos dados, optamos pela realização de entrevistas semiestruturadas. Compreendemos que a entrevista está além do modelo instituído, no qual o/a pesquisador/a pergunta e o/a participante responde. Entendemos essa estratégia a partir de 

e-ISSN 2016/Atual: 2525-7870 | e-ISSN 2015/2016: 2447-018X

Rosa Silveira (2007) como uma construção cultural e socialmente situada entre entrevistador/a e entrevistado/a; é nessa arena de significados que produzem outras verdades, experiências, histórias, olhares. Nessa direção, as entrevistas podem ser descritas:

[...] como eventos discursivos complexos, forjados não só pela dupla entrevistador/entrevistado, mas também pelas imagens, representações, expectativas que circulam -de parte a parte- no momento e situação de realização das mesmas e, posteriormente, de sua escuta e análise (SILVEIRA, 2007, p. 118).

No campo teórico em que estamos inseridas, o dos Estudos Culturais a partir do viés pós-estruturalista, ao analisar as narrativas produzidas é preciso considerar que não há nada "oculto" em suas falas que necessite ser revelado. Temos que nos deter ao que foi dito, ficar no nível do discurso, sem esquecer que a interação entre entrevistado/a e entrevistador/a constitui-se em razão de relações de poder. Em relação a isso, Rosa Silveira salienta que, se por um lado nossa representação usual de entrevistas “[...] tenda a incluir um sujeito perguntando, 'querendo saber', questionando, e chegando, em certas ocasiões, a encurralar o entrevistado [...], o entrevistado também lança mão de numerosas estratégias de fuga, substituição e subversão dos tópicos propostos" (2007, p. 124).

Considerando tais entendimentos, na realização das entrevistas não buscamos encontrar respostas absolutas sobre o/a participante ou algo escondido nas entrelinhas que pudesse revelar "a verdade" sobre os fatos. Entendemos a entrevista "[...] como a instância central que, somada às outras, traz informações fundamentais acerca do vivido e possibilita uma interpretação (mesmo que provisória e parcial)" (ANDRADE, 2012, p. 175). Assim, realizamos quatro (4) entrevistas com dois professores e duas professoras de ciências que trabalham em distintas escolas do município do Rio Grande, RS. Com duração média de sessenta minutos, aconteceram nos locais escolhidos pelos/as entrevistadas e foram gravadas em áudio. Uma entrevista foi realizada no local de trabalho da entrevistada e as demais no Centro de Educação Ambiental Ciências e Matemática (CEAMECIM) pertencente à Universidade Federal do Rio Grande - FURG.

Para a realização das entrevistas, foi produzido um roteiro que serviu para guiar as discussões, no qual as perguntas eram abertas e buscavam conhecer a formação do/a docente, suas práticas, de que forma entrou em contato com o livro de Mariana, quais as atividades desenvolvidas a partir do material, mudanças em sua prática em decorrência do trabalho com o livro, percepções em relação ao trabalho desenvolvido, entre outros. Conduzimos as entrevistas como uma conversa dirigida, de maneira mais informal, procurando criar um espaço em que o/a participante se sentisse à vontade para compartilhar suas experiências. 
Considerando os aspectos éticos, foi elaborado, entregue e assinado por todos/as entrevistados/as um Termo de Consentimento Livre e Esclarecido, que apresentava os objetivos e os caminhos desenvolvidos ao longo da pesquisa. Também foi pedido que cada participante escolhesse um pseudônimo para ser utilizado na pesquisa, a fim de promover seu anonimato. A transcrição das entrevistas foi encaminhada por e-mail para os/as docentes, para que pudessem modificar questões que não estivessem claras ou que gostariam de alterar em suas falas.

$\mathrm{Na}$ análise das narrativas, é preciso atentar para o que foi dito, o que está posto, ao invés de ficar procurando o que o/a entrevistado/a gostaria de dizer com aquilo. Como aponta Rosa Fischer, é necessário

[...] tentar escapar da fácil interpretação daquilo que estaria "por trás" dos documentos, procurando explorar ao máximo os materiais, na medida em que eles são uma produção histórica, política, na medida em que as palavras são também construções, na medida em que a linguagem também é constitutiva das práticas (2001, p. 199).

Ancorados nessa perspectiva, ao olharmos para as narrativas, mostrou-se necessário atentar para as relações de poder-saber que se encontram envolvidas em sua produção. Antes de abordar as análises que compõem este artigo, apresentamos brevemente os/as docentes participantes da pesquisa.

Alice leciona desde 2012, possui graduação em Ciências Biológicas licenciatura. Além disso, é mestre e doutora pelo programa de Pós-graduação em Educação em Ciências: Química da Vida e Saúde.

Clarice formou-se, em 2006, no curso de Química Licenciatura habilitação em Ciências e leciona ciências desde então. É mestre em Educação Ambiental.

Daniel concluiu em 2002 a licenciatura em Física e desde então leciona a disciplina. Em 2013, passou a trabalhar também com ciências. Na época da nossa entrevista, estava cursando mestrado.

Morpheu é graduado em Oceanologia e tem mestrado e doutorado na mesma área. A licenciatura em Biologia é recente, assim como sua atuação docente, iniciada em 2015.

destacar destaca-se que todos/as as entrevistados/as possuem pós-graduação e participam de cursos de formação continuada. Entendemos,portanto, que esses fatores contribuem para uma prática docente diferenciada, ou seja, eles/as utilizam inúmeros recursos didáticos em suas aulas como, por exemplo, revistas, livros paradidáticos, games e internet e realizam experimentos, vídeos, músicas, entre outros. Não queremos dizer que a utilização de 

e-ISSN 2016/Atual: 2525-7870 | e-ISSN 2015/2016: 2447-018X

tais recursos torna suas aulas melhores do que a de profissionais que não os utilizam, mas apontamos apenas que esse grupo está mais propicio a experimentar novas formas de lecionar. Uma vez apresentados os sujeitos da pesquisa, passamos à análise de suas narrativas.

\title{
5. Analisando as narrativas referentes ao livro "Os 15 anos de Mariana"
}

As análises apresentadas estão divididas em três eixos, produzidos a partir do agrupamento das narrativas que estabeleciam semelhança entre si. O primeiro eixo aponta as motivações que propiciaram a utilização do livro, o segundo apresenta as atividades realizadas a partir do livro e o terceiro aborda que tipo de corpo o livro possibilitou discutir. As narrativas apresentadas a seguir compõem o eixo que aborda as motivações para a utilização do livro de Mariana nas práticas docentes. Elas apontam os motivos que conduziram os/as docentes a trabalharem com o livro de Mariana:

\begin{abstract}
CLARICE - eu acho que o legal dele é também a gente trabalhar não só com o que tá ali, mas o que eles produzem a partir daquilo ali, por exemplo, eles podem produzir um outro livro, criar uma outra Mariana, criar uma outra personagem qualquer para contar as histórias deles. Então eu acho que o livro também traz essa outra possibilidade deles contarem outra história a partir do livro. Eu tive uma aluna que escreveu quatro folhas de caderno dos dois lados a partir do livro, que ela contou toda uma história que provavelmente aconteceu com ela e ela criou um personagem. Então eu acho que esse tipo de coisa, eu acho bem legal a partir do livro.
\end{abstract}

DANIEL - Achei bem interessante o livro, já que não era uma leitura maçante, aqueles troços chatos de usar, de ler sempre tentando me colocar na posição do aluno, mas em geral é bem tranquilo de ler, bem gostoso de ler. Depois eles também gostaram do livro, também tiveram a mesma opinião, é fácil de ler e bem tranquilo.

As narrativas apresentadas indicam que o caráter lúdico e a linguagem narrativa do livro, através da qual a história é contada, contribuíram para sua utilização em sala de aula. Em relação às características dos livros paradidáticos, Norma Ferreira e Elizabete Melo (2006) apontam que a formatação desses materiais era semelhante aos livros de literatura infanto-juvenil com “[...] poucas páginas, bem coloridas e ilustradas e uma aparência gráfica bem cuidada (qualidade do papel, legibilidade do texto, diagramação). Abordando geralmente um tema por livro, os conteúdos eram apresentados em forma de narrativas" (2006, p. 196). Ao apresentar tais características, o livro de Mariana motiva os/as estudantes ao envolvê-los no cotidiano dos personagens e torna-se atraente aos/as docentes, pois aborda os conteúdos relativos ao corpo humano na perspectiva da ludicidade.

A professora Clarice, em sua narrativa, descreve que poder utilizá-lo como base para pensar em outras histórias a motiva a fazer uso do livro. Assim, a história de Mariana serve de subsídio para que outras histórias sejam contadas e possibilita que os/as estudantes sintam-se 

e-ISSN 2016/Atual: 2525-7870 | e-ISSN 2015/2016: 2447-018X

à vontade para relatar angústias, medos, desejos, sonhos. O trabalho com uma nova metodologia pode, no início, criar receio no/a docente, visto que sair da nossa zona de conforto pode ser desafiador, mas é preciso apostar em novos caminhos, como aponta o professor Morpheu:

eu estava muito preocupado com a questão do conteúdo, mesmo, corpo humano, o tempo que eu tinha, a falta de tempo, de planejamento das estratégias, o que mais me pegou, eu me vi muito mergulhado em cima da sequência que o livro didático oferecia [...] e aí o livro paradidático entrou e aí eu falei, eu tenho que apostar, eu tenho que apostar neles, é uma turma bem problemática, eu tenho bastante problemas de indisciplina, várias vezes eu tenho que tirar alunos para fora da sala porque eles começam a batucar, começam a cantar, não querem fazer as atividades e aí começa a atrapalhar os outros grupos que querem trabalhar - eles trabalham muito em grupos, duplas, trios, já têm suas afinidades, aí eu falei, eu tenho que apostar, mas com muito medo, muito receio. [...] eu encontrei no livro paradidático uma maneira de motivação, para eles se motivarem a discutir questões polêmicas sobre drogadição, tabagismo, aí vão vindo os temas, Alzheimer, agora nós vamos puxar novamente o Alzheimer porque eu trabalhei com sistema nervoso.

CLARICE - eu trabalho normalmente com o oitavo ano porque é o conteúdo, eu acho que é o tipo de assunto que tem muito interesse, tem muita relação com eles.

O livro paradidático também se apresenta como uma possibilidade de romper com a abordagem presente no livro didático, que por vezes pode mostrar-se distante das vivências dos/as estudantes. Os materiais paradidáticos têm por objetivo "[...] articular os conhecimentos que devem ser apreendidos/ensinados de maneira mais simples e cotidiana, ou seja, mais próxima da realidade corriqueira dos educandos" (JESUS, 2015). Então, ao apresentar como temática os preparativos para uma festa de 15 anos, o livro de Mariana busca abordar o corpo humano vinculado a experiências e a acontecimentos que estão presentes no cotidiano dos/as estudantes, favorecendo uma aprendizagem mais prazerosa.

A utilização do material pelos/as docentes ocorreu de distintas formas: alguns discutiram todo o livro, outros selecionaram capítulos para serem abordados. Nesse segundo eixo, apresentamos e discutimos as atividades realizadas a partir do livro "Os 15 de Mariana: um convite a outras aprendizagens sobre corpos". Os/as docentes, ao serem questionados/as sobre as atividades desenvolvidas, apontam:

Daniel - um grupo de maneira totalmente informal resolveu fazer aquela experiência do jornal com o protetor e sem protetor $^{5}$, aí eles fizeram e ampliaram um pouco essa experiência e só mostraram pra turma. Esse só mostraram é um pouco simplista, mas eles mostraram pra turma.

5 . A experiência relatada pelo docente consiste em expor ao sol objetos com e sem protetor solar, a fim de observar os efeitos da radiação solar. Nessa prática, os/as estudantes utilizaram jornais, folhas de babosa e folhas de ofício como materiais. 
Clarice - a gente trabalhou a partir do que tinha lá e a partir da realidade deles, porque apesar de ser zona rural muita coisa para eles é uma coisa natural, por exemplo, rede social, a questão da família, a questão dos limites que a família impõe, essas coisas, tudo isso a gente conseguiu trabalhar a partir do texto e, no final, criaram uma historinha, eles criaram um personagem e criaram uma historinha sobre esse personagem.

As falas expostas indicam que o trabalho com o livro paradidático possibilitou que os/as estudantes discutissem e pesquisassem temas de seu interesse, que estão em seu cotidiano, como, por exemplo, radiações solares, relações familiares, drogas, doenças sexualmente transmissíveis, entre outros. Tais temas, muitas vezes, não são encontrados nos livros didáticos de ciências e, quando o são, como no caso das drogas e das doenças, são apresentados pelo viés científico entrelaçado ao discurso moral, desconsiderando, assim, os fatores culturais, sociais, históricos e psicológicos envolvidos. Em relação a esse distanciamento existente entre o livro didático e os/as estudantes, Elisangela Freitas e Isabel Martins apontam que:

[...] a questão é abordada do ponto de vista biológico/fisiológico deixando de contemplar as questões culturais, socioeconômicas e sociais. As questões referentes ao fumo, uso de drogas, ingestão de bebidas alcoólicas e direção perigosa aparecem de maneira fragmentada e descontextualizada. Em geral, não geram discussões ou permitem que os alunos expressem dúvidas ou que permitam estabelecer relações entre estes comportamentos e questões pessoais, o que pode não contribuir para uma mudança no comportamento (2008, p.13).

Nas narrativas dos docentes, podemos observar que o primeiro contato dos/as estudantes com o livro foi através da leitura proposta pelo/a professor/a, feita de forma individual ou coletiva. A partir dessa leitura, os/as estudantes elencaram temas de seu interesse que estabeleciam relação com o livro e, posteriormente, foram desenvolvidas as atividades descritas nas narrativas a seguir.

Daniel - eu pedi a produção textual, eles escreveram, fizeram uma releitura da história, aí, pra continuar trabalhando em cima [...] eles ilustraram alguns fizeram uma história em quadrinhos, outros fizeram simplesmente ilustrações relacionadas à historinha que eles tinham criado, mas não diretamente ao livro, então ilustraram a história que eles tinham criado. Aí, o que acontece nessas aulas de fazer história, de fazer ilustração, vão surgindo as dúvidas, os comentários vão surgindo, vai chegando até a gente o aculturamento que eles têm, então, tipo, tem uma parte que fala de diabetes da avó, então tinha uma menina que tinha avó com diabetes e veio conversar essa parte. [...] quando chegou especificamente nas partes de sexualidade, de prevenção de doenças, quando falou de camisinha foi bastante conversado.[...] todo mundo quis falar, conversar, trocar ideias nesses momentos na verdade eu ficava mais de fora olhando do que participando, mesmo, porque eles... é claro eu tinha que participar e intervir quando tinha alguma informação, 

e-ISSN 2016/Atual: 2525-7870 | e-ISSN 2015/2016: 2447-018X

assim, escandalosamente absurda e, assim, em geral, ele já têm as informações necessárias.

Morpheu - A gente começou a leitura, no começar da leitura eu já propus: olha, precisamos de personagens, quem vai ser quem? Aí foi uma loucura porque todo mundo queria ser tudo e depois foram mudando ninguém queria ser a avó Clô. [...] $e$ aí saíram as temáticas e eu fui puxando as temáticas do que vinha, por exemplo, drogadição, a questão do sistema tegumentar, que é a pele, fazer tatuagem ou não, já se preparando para a festa, então fui tentando encaixar os temas pra ficar prazeroso pra eles, então começou um teatro, mas na verdade é uma leitura, é uma leitura dinâmica dos personagens e os personagens vão sendo trocados, eles toparam e acharam o máximo, aí eu disse: ufa! Alguma coisa que entrou na zona de motivação deles e aí eu dei um passo adiante: gente, a gente podia montar mesmo um teatro, toda a história, mostrar pra todo mundo. Aí ficaram: ai, não sei.

Alice - Esse ano, quando eu entreguei para eles, a gente leu alguns capítulos em sala de aula e eles levaram para casa [...] o que aparece é que também tem uma questão da turma, do interesse de turma, [...] apareceu um trabalho, apenas, sobre doenças sexualmente transmissíveis. Não foi um tema que eles se empolgaram de trabalhar, foi a radiação, Alzheimer e os alimentos, eu acho, foi bem isso a maior parte. Teve trabalhos sobre lei seca bem vinculada à questão do trânsito, a bebida, $e$ só foram esses temas que apareceram.

As narrativas apresentadas indicam que as propostas envolveram os/as estudantes, pois partiram de saberes presentes em seus cotidianos. Em relação a essa articulação entre o conhecimento científico e o popular, André Martins (2010, p. 19) aponta que "é fundamental que os professores conheçam e trabalhem com esses saberes. É no diálogo do cotidiano com o científico que a escola deve atuar".

Os/as entrevistados buscaram criar um ambiente no qual os/as estudantes se sentissem confortáveis, seguros para compartilhar suas experiências, como, por exemplo, o caso da menina que a avó tem diabetes, citado pelo Daniel. Em relação a isso, Angel Pino (1997) diz que cabe aos/as professores/as propiciarem situações que permitam integrar, harmoniosamente, a afetividade e os conteúdos específicos. Esse clima criado pelos/as docentes também possibilitou aos/as estudantes expressarem suas curiosidades acerca de distintos temas e incentivou o diálogo e a argumentação entre os envolvidos/as. Assim, entendemos que:

[...] estimular o aluno, incitar a sua curiosidade, fazer com que ele coloque todos os sentidos para funcionar durante uma aula, trará bons resultados na sua aprendizagem, de forma que, ao entrar numa sala de aula convencional ou no laboratório, ele já espera sair dali diferente de quando entrou, e feliz, pois o professor se valeu dos conhecimentos que a sala possuía para iniciar um assunto novo, construindo assim o conhecimento relevante, aquele que será base para as mais diversas associações que os alunos poderão fazer, sabendo então se posicionar diante de novas informações e não apenas consumi-la (FALA, et. al. 2010, p.149$150)$. 

e-ISSN 2016/Atual: 2525-7870 | e-ISSN 2015/2016: 2447-018X

Dessa forma, as atividades desenvolvidas a partir do livro "Os 15 anos de Mariana" favoreceram a apropriação de distintos conhecimentos que estabelecem estrita relação com as vivências dos/as estudantes, tornando o ensino mais dinâmico e interessante. Além disso, motivaram os/as estudantes a estudar sobre o corpo, como apontou o professor Morpheu:

\begin{abstract}
Morpheu - a gente conversou sobre álcool, tudo que era droga, era o que afetava ou alterava o funcionamento de alguma maneira, aí veio essa história do energético, que eu sei que eles usam com álcool para disfarçar, e quanto ao tabaco eles relatavam que os pais fumavam. Mas saiu, sim, esse tema das drogas ilícitas, porque ali tem ponto de tráfico, tem o filho de alguém lá que é traficante, é filho do traficante, eles têm aquelas brincadeiras sem graça que eles fazem, mas foi trabalhado essa questão de que eи preciso cuidar do meи corpo, por que eи vou ficar na ilusão? Trabalhei, também, questões éticas, questões sobre o direito do corpo, aí eles perguntam: professor, se a pessoa bebe enquanto se alimenta o efeito do álcool é menor? É, o efeito do álcool é menor, mas ele não deixa de ter um efeito, então o sistema digestório vai trabalhar aquele álcool junto com o alimento, vai ter uma sobrecarga. A pessoa vai ficar mais embriagada, ou menos embriagada? Vai ficar menos embriagada do que se só ingerir o álcool, porque o sistema vai metabolizar o álcool. Então a gente tenta ir trazendo como funciona o corpo.
\end{abstract}

O ensino pautado na curiosidade e no interesse dos/as estudantes contribui para o desenvolvimento de uma aprendizagem ancorada na experiência, não na simples memorização de conceitos. A partir da fala do professor Morpheu podemos entender que os assuntos discutidos em sala de aula estão presentes na vida dos/as estudantes. Logo, esse docente buscou promover um currículo que, ao invés de excluir, inclui as vivências dos/as estudantes no processo de ensino-aprendizagem. Ao utilizarem tal estratégia, os/as professores/as possibilitaram a promoção de um aprendizado baseado na liberdade, no interesse, na satisfação e no encantamento com a descoberta do conhecimento. (MEYER, 2010).

Em relação ao ensino do corpo humano, é necessário romper com a visão fragmentada apresentada nos livros didáticos e nos currículos escolares. Ao apresentá-lo como um sistema integrado, possibilitamos aos/as estudantes "relacionar o conteúdo estudado ao seu cotidiano, já que o corpo humano, que é o objeto de estudo, está presente a todo o momento em sua vida" (CUNHA et. al. 2010, p. 69). Em relação a isso, a professora Alice destaca que é fácil trabalhar com elementos presentes no cotidiano dos/as estudantes:

Alice - ao trabalhar o corpo humano, é muito propício trazer essa questão contextualizada, porque é muito fácil, está ali no jornal [...]. Então, eu sempre trago uma atividade que consiga relacionar com o que eles estão comendo, com o que eles estão fazendo, com a ida deles ao sol, a gente trabalhou o câncer também, quais eram os tipos de câncer que mais ocorriam, eu trouxe um texto falando um pouquinho sobre o câncer [...]. Mais ou menos por aí que vou procurando trazer 
RELACult - Revista Latino-Americana de Estudos em Cultura e Sociedade

Revista Latinoamericana de Estudios en Cultura y Sociedad | Latin American Journal of Studies in Culture and Society

V. 02, Ed. Especial, dezembro, 2016, p. 166-183 | periodicos.claec.org e-ISSN 2016/Atual: 2525-7870 | e-ISSN 2015/2016: 2447-018X

algo que está no dia-a-dia deles. [...] Na maioria dos assuntos abordados em sala de aula eu sempre trago alguma coisa relacionada ao cotidiano deles, ao contexto deles.

Portanto, a história da Mariana abre espaço para que o corpo seja compreendido como uma estrutura em constante movimento, que afeta e é afetado, que produz e é produzido, que está em constante processo de construção. Nesse eixo, apresentamos o tipo de corpo que o livro possibilitou ser discutido pelos/as docentes.

Ao serem indagados sobre o tipo de corpo que o livro abre espaço problematizar no espaço escolar, os/as entrevistados/as apontam:

Alice - mostrar esse corpo que não é um corpo só biológico, esse corpo só dividido em partes, eu sempre procuro trabalhar ele todo integrado, porque não funciona assim, cada parte funciona e deu, todo ele vai funcionar porque vai entrar o oxigênio, o sistema circulatório funciona ao mesmo tempo, então não dá para separar. Fazer esses links, sempre tem uma linha de raciocínio no que eu vou trabalhar.

Clarice - A gente monta vários tipos de Frankenstein com vários pedaços pra gente discutir a questão da moda, da mídia, o que é bonito, o que é feio, na antiguidade o que era bonito, o que agora é bonito para conversar com eles, então, eu tento trabalhar muito essa questão do corpo, deles se aceitarem porque eu acho que na adolescência é bem complicado, é bem difícil.

Morpheu - Bom, trabalhei um corpo em transformação, visto que a idade deles já é uma idade de transformação [...]. Eu vejo o corpo como nosso instrumento biológico, mas aí entram as concepções religiosas, então ele é instrumento para a gente interagir com o ambiente, eu tenho que ver como funciona, então acho que é isso que eu tento interagir com os alunos, como é que o meu corpo funciona. Então o livro paradidático está sendo fator de motivação pra eles estudarem sobre o corpo humano.

Essa concepção de corpos nas falas apresentadas indica que os/as docentes os entendem como não formados apenas pela biologia, mas também interpelados pela cultura, pelo consumo, pela moda, entre outros. São construções socioculturais, que ostentam as marcas de sua época, classe social, cultura, política, ou seja, exercem sentido dentro das redes de significação que compartilham. Desse modo, é essa a concepção de corpos que deve orientar o seu ensino, não a visão biológica, compartimentada, a qual apresenta que

[...] o ser humano cabe no ensino apenas aos pedaços. Nas séries iniciais ele entra divido em cabeça, tronco e membros. Mais adiante, o lugar do corpo humano é o lugar dos sistemas, em que cabe apenas um sistema por vez, o digestivo, o circulatório, o reprodutor, o respiratório... No ensino médio o corpo se "espreme" nas células e se estudam as funções celulares e moleculares, que já não são exclusivas do corpo humano, mas universais para os seres vivos. Parece que ao avançarmos na escolaridade, avançamos também na fragmentação desse corpo (TRIVELATO, 2005, p. 122) [grifos da autora]. 

e-ISSN 2016/Atual: 2525-7870 | e-ISSN 2015/2016: 2447-018X

Ao abordar os distintos discursos que atuam na produção dos corpos, além do biológico, os/as docentes possibilitam que os/as estudantes compreendam a estreita relação entre as práticas sociais e culturais e a construção dos corpos, como aponta o professor Morpheu "eu não consigo falar sobre corpo sem falar das reações, da questão social e da questão étnica”. Logo, os corpos discutidos em sala de aula possibilitaram aos/as estudantes o entendimento de que a sua construção é para além da materialidade biológica, como aponta Silvana Goellner:

Um corpo não é apenas um corpo. É também o seu entorno. Mais do que um conjunto de músculos, ossos, vísceras, reflexos e sensações, o corpo é também a roupa e os acessórios que o adornam, as intervenções que nele se operam, a imagem que dele se produz, as máquinas que nele se acoplam, os sentidos que nele se incorporam, os silêncios que por ele falam, os vestígios que nele se exibem, a educação de seus gestos ... enfim, é um sem limite de possibilidades sempre reinventadas e a serem descobertas (2013, p.31).

Pode-se afirmar que os/as docentes entrevistados possibilitaram rupturas no currículo vigente, especialmente no que é concedido ao estudo do corpo humano. Tais rupturas produziram efeitos nos/as professores/as, nos/as estudantes e em toda a comunidade escolar, como podemos observar na narrativa do professor Morpheu:

quando a gente trabalhou sistema tegumentar tinha uma sugestão de usar um fio de cabelo para pesar uns DVDs, até sete DVDs dava $7 x 15$ gramas, que era o que um fio de cabelo suportava. Aí a gente trabalhou isso, e cada guria tem um tipo de cabelo, foi isso que elas começaram a perceber, umas usam química, tinha uma mestiça, não totalmente negra, mas o cabelo entre aspas mais crespo, perguntava mas guria tu alisa esse cabelo? Tu usa muita química por que tu faz isso? Eu gosto assim. Será que o teu cabelo é forte? O cabelo realmente não resistiu ao peso dos DVDs. Aí eu falei olha a química que tu tá usando no teu cabelo pode tá alterando, então eu trabalho o corpo deles, o corpo em transformação.

A fala apresentada aponta que, ao propor um currículo que inclua as experiências dos/as estudantes, ele torna-se interessante e possibilita aos/as estudantes questionarem determinadas práticas realizadas. Dessa forma, o/a estudante pode construir um saber contextualizado, a qual permite estabelecer relações entre os conceitos estudados e as situações do seu dia-a-dia.

\section{Considerações}

Os materiais paradidáticos procuram estabelecer relação entre os conteúdos escolares e os temas presentes no cotidiano, buscando promover, assim, uma aprendizagem prazerosa. Tendo como pano de fundo a festa de 15 anos, o livro "Os 15 anos de Mariana: um convite a 

e-ISSN 2016/Atual: 2525-7870 | e-ISSN 2015/2016: 2447-018X

outras aprendizagens sobre corpos" possibilita a compreensão de que os corpos são construções biossociais, interpelados por múltiplos discursos como, por exemplo, da medicina, da moda, do consumo, da saúde, etc.

As entrevistas realizadas com docentes que desenvolveram atividades a partir do material mencionado indicam que a linguagem narrativa do material e a temática abordada foram fatores importantes para sua escolha e seu uso nas práticas escolares. As atividades realizadas pelos/as professores/as tendo como ponto de partida o livro de Mariana possibilitaram que os/as estudantes realizassem pesquisas e experimentos envolvendo temas do cotidiano, relacionados com suas vivências e experiências. Os conhecimentos obtidos através desses processos foram socializados tanto em sala de aula, para os/as colegas de turma, como em um evento realizado na escola, que contou com a presença de toda a comunidade escolar.

A relação estabelecida entre os temas estudados e as experiências dos/as estudantes potencializa a construção de conhecimentos e propicia um ambiente de aprendizagem prazeroso. O corpo que o livro "Os 15 anos de Mariana" possibilitou ser discutido no espaço escolar está próximo dos corpos dos/as estudantes, exibe marcas de gênero, bronzeado, velho, que se machuca, que engorda, que tem espinhas, é um corpo plural, múltiplo, diferente do corpo estático e compartimentado representado nos livros didáticos. Desse modo, entendemos que o trabalho desenvolvido pelos/as docentes entrevistados/as contribuiu para a promoção de um ensino que apresenta os corpos não como estanques e universais, mas, longe disso, os mostra como produções em constante processo de construção e reconstrução.

\section{Referências}

ANDRADE, Sandra dos Santos. A entrevista narrativa (re)significada nas pesquisas educacionais pós-estruturalista. In: MEYER, Dagmar E; PARAÍSO, Marlucy A. (Orgs.) Metodologias de pesquisa pós-críticas em educação. Belo Horizonte: Mazza, 2012.

CAMARGO, Tatiana Souza de. SOUZA, Nádia Geisa Silveira de. Corpo, comida e cultura: Discussão e problematização os padrões contemporâneos de beleza/saúde no ensino de ciências. Revista Horizontes, v. 30, n. 2, p. 69-79, jul./dez. 2012.

CONNELLY, Michael; CLANDININ, Jean. Relatos de experiencia e investigación narrativa. In: LARROSA, J. et al. Déjame que te cuente: ensayos sobre narrativa y educación. ed. Barcelona: Laertes, 1995. p.11-59.

CUNHA, Ana Maria de Oliveira.; FREITAS, Denise de.; SILVA, Elenita Pinheiro de Queiroz. O corpo da ciência, do ensino, do livro e do aluno. In: PAVÃO, Antônio Carlos (Org.) Coleção Explorando o Ensino. Ciências: ensino fundamental. v. 18. Brasília: Ministério da Educação, Secretaria de Educação Básica, 2010. p. 61-76. 
FALA, Angela Maria; CORREIA, Elisete Marcia; PEREIRA, Humberto D'Muniz. Atividades práticas no ensino médio: uma abordagem experimental para aulas de genética. Ciência e cognição. Rio de Janeiro , v. 15,n. 1,p. 137-154. 2010. Disponível em $<$ http://pepsic.bvsalud.org/scielo.phpscript=sci_arttext\&pid=S180658212010000100012\&lng $=$ pt\&nrm=iso $>$. acessado em dez. 2015.

FERREIRA, Norma Sandra de Almeida; MELO, Elizabete Amorim de Almeida. Livros paradidáticos de língua portuguesa: a nova fórmula do velho. Pro-Posições. v. 17, n. 2. 2006. p. 195-209.

FREITAS, Elisangela Oliveira de; MARTINS, Isabel. Transversalidade, formação para a cidadania e promoção da saúde no livro didático de ciências. Ensino, Saúde e Ambiente, v.1, n.1. 2008. p. 12-28.

FISCHER, Rosa Maria Bueno. Foucault e a Análise do discurso em educação. Cadernos de Pesquisa, São Paulo, n. 114, p. 197-223, nov. 2001.

FOUCAULT, Michel. Nietzsche, a genealogia e a história. In: Microfísica do poder. 28. ed. Rio de Janeiro: Paz e Terra, 2014. 431p.

FURLANI, Jimena. O Bicho vai pegar! - um olhar pós-estruturalista à Educação Sexual a partir de livros paradidáticos infantis. Tese de doutorado apresentada no Programa de PósGraduação em Educação, da Universidade Federal do Rio Grande do Sul, UFRGS. 2005, $272 p$.

GOELLNER, Silvana. A produção cultural do Corpo. In: LOURO, Guacira; FELIPE, Jane; GOELLNER, Silvana. Corpo, gênero e sexualidade um debate contemporâneo na educação. 9.ed. Petrópolis: Vozes, 2013. p. 30-42.

JESUS, Fernando. O Negro no Livro Paradidático: Analisando o Livro "Capoeira". Revista Horizontes, v. 33, n. 1. 2015. p. 123-138.

LARROSA, Jorge. Narrativa, identidad y desidentificación. In: LARROSA, J. La experiencia de la lectura. Barcelona: Laertes, 1996. p. 461-482.

MARTINS, André Ferrer. Palavras, Textos e contextos. In: PAVÃO, Antônio Carlos (Org.) Coleção Explorando o Ensino. Ciências: ensino fundamental. v. 18. Brasília: Ministério da Educação, Secretaria de Educação Básica, 2010. p. 11-24.

MEYER, Mônica. De corpo e alma: conversa ao pé do ouvido. In: PAVÃO, Antônio Carlos (Org.) Coleção Explorando o Ensino. Ciências: ensino fundamental. v. 18. Brasília: Ministério da Educação, Secretaria de Educação Básica, 2010. p. 77-88.

PINO, Angel. O Biológico e o Cultural nos processos cognitivos. In: encontro de pesquisadores de psicologia de ensino e ciência. Belo Horizonte. Teoria e Pesquisa em Ensino de Ciência. Campinas: gráfica da Unicamp, 1997. v. 1. p. 37-55. 
QUADRADO, Raquel Pereira. Práticas Bioascéticas Contemporâneas: notas sobre os corpos masculinos nas comunidades que discutem cirurgia plástica na rede social Orkut. Rio Grande: FURG/PPGEC, 2012. Tese de doutorado, 2012.

RIBEIRO, Paula Regina Costa; LONGARAY, Deise Azevedo (org.) Os 15 anos de Mariana: um convite a outras aprendizagens sobre corpos. Rio Grande: FURG. 2013. 144p.

SANTOS, Luiz Henrique Sacchi dos. Incorporando "outras" representações culturais de corpo na sala de aula. In: OLIVEIRA, D. (Org.). Ciências na sala de aula. Cadernos de Educação Básica, vol. 2. Porto Alegre: Mediação, 2002. p.97-112.

SILVA, Tomaz Tadeu da. Currículo e identidade social: territórios contestados. In:__(Org). Alienígenas na sala de aula - uma introdução aos estudos culturais em educação. 11. ed. Petrópolis: Vozes, 2013, p. 185 - 202.

SILVEIRA, Rosa Maria Hessel. A entrevista na pesquisa em educação - uma arena de significados. In: COSTA, Marisa Vorraber. (Org.). Caminhos Investigativos II: outros modos de pensar e fazer pesquisa em educação. 2. ed. Rio de Janeiro: Lamparina, 2007. p. 117-138.

TRIVELATO, Sílvia Luzia Frateschi. Que corpo/ser humano habita nossas escolas? In: MARANDINO Martha; SELLES, Sandra Escovedo; FERREIRA, Marcia Serra; AMORIN, Antônio Carlos (orgs.). Ensino de Biologia: conhecimentos e valores em disputa. Niterói: EDUFF, 2005. p. 121-130. 